\title{
No fio da navalha: Entre a garantia dos direitos e a ameaça contra os próprios direitos na atuação do assistente social na cidade de Parintins - Amazonas
}

\section{In razor wire: Between the guarantee of rights and the threat against their own rights in the work of the social worker in the city of Parintins - Amazonas}

\author{
Alice Alves Menezes Ponce de Leão Nonato* \\ Beatriz Borges Viana**
}

\begin{abstract}
Resumo: A precarização do trabalho do assistente social afeta o direcionamento de suas ações e a subjetividade do profissional, em um contexto onde a retração dos direitos ameaça a reprodução da vida. O assédio moral e o neoconservadorismo se inscrevem na prática profissional e no enfrentamento da questão social. Este artigo objetiva problematizar os efeitos das condições precarizadas de trabalho dos assistentes sociais no enfrentamento das mazelas sociais e nos dilemas éticos que perpassam o cotidiano profissional. A metodologia é baseada em uma pesquisa qualitativa, com aplicação de entrevistas a 12 assistentes sociais inseridas em diversos espaços socio-ocupacionais em Parintins, Amazonas. Os resultados apontam que a presença atuante do CRESS-AM é necessária na fiscalização das condições de trabalho e na segurança dos profissionais.
\end{abstract}

Palavras-Chave: Assistente Social. Trabalho. Direitos.

\begin{abstract}
The precariousness of the social worker's affects the direction of his actions and the subjectivity of the professional, in a context where the retraction of rights threatens the reproduction of life. Bullying and neoconservatism are part of professional practice and confronting the social question. This article aims to problematize the effects of the precarious working conditions of social workers in coping with social ills and the ethical dilemmas that pervade everyday life. The methodology is based on a qualitative research, with the application of interviews to 12 social workers inserted in several socio-occupational spaces in Parintins, Amazonas. The results indicate that the active presence of CRESS-AM is necessary in the supervision of working conditions and in the safety of professionals.
\end{abstract}

Keywords: Social Worker. Job. Rights.

"Doutoranda em Sociedade e Cultura na Amazônia pela Universidade Federal do Amazonas (PPGSCA/UFAM), Mestre em Serviço Social e Sustentabilidade na Amazônia e Professora do Curso de Serviço Social da UFAM, campus Parintins - AM. Email: allicyponce@hotmail. com.

*Bacharel em Serviço Social pela Universidade Federal do Amazonas, campus Parintins - AM. Email: beatriz_vi_ana@hotmail.com. 


\section{Introdução}

O caráter contraditório da profissão de Serviço Social, por atender os interesses das duas classes fundamentalmente opostas na sociedade, gera um dilema na identificação orgânica de alguns profissionais com os interesses da classe que demanda os serviços sociais, à qual também pertencem os assistentes sociais, a classe trabalhadora.

Raichellis (2011) sinaliza que, apesar de termos um projeto profissional vinculado aos interesses da classe trabalhadora, muitos assistentes sociais têm dificuldades em identificar-se como pertencentes a essa classe. Esse distanciamento impede que tratemos com o mesmo grau de importância os dilemas, o sofrimento e o adoecimento que perpassam o cotidiano de trabalho dos assistentes sociais enquanto trabalhadores assalariados inseridos no contexto de retração de direitos e dos reflexos da precarização do trabalho através da flexibilização, da subcontratação e do trabalho temporário.

O nível de formação profissional, a imagem de representantes da esfera pública ou da empresa privada em que os assistentes sociais trabalham e o poder que confere ao assistente social a decisão de inclusão ou exclusão dos usuários no acesso às políticas sociais frente aos parcos recursos institucionais faz com que, na prática, alguns profissionais se identifiquem como classe burguesa e não tanto como profissionais pertencentes ao conjunto da classe trabalhadora.

Entretanto, para Castells (2008), os efeitos da precarização do trabalho atingem tanto os desqualificados, os trabalhadores com baixa escolarização, mas também os qualificados, os profissionais de nível superior, onde todos podem constituir-se como os "sobrantes do capital". Assim, os assistentes sociais também estão no "fio da navalha", de forma ainda mais problemática por serem os profissionais que atuam na perspectiva de acesso das classes subalternas aos direitos sociais. Mas, como garantir direitos se os próprios direitos desses profissionais estão sendo violados?

O adoecimento e o sofrimento são decorrentes do assédio moral e do neoconservadorismo que tolhem o direcionamento das ações profissionais frente a um contexto de trabalho com vínculos empregatícios fragilizados, com sobrecarga de trabalho e redução do tempo livre. Somados a isso, tem-se o aprofundamento das condições abjetas de vida das classes que demandam os serviços sociais e um enfrentamento parcializado através de políticas sociais mínimas, focalizadas, seletivas e fragmentadas.

Esses dilemas situam o trabalho do assistente social entre o prazer e o sofrimento; o prazer, pelo compromisso profissional circunscrito aos valores do projeto ético-político na perspectiva de construção de uma nova ordem societária onde a ampliação dos direitos humanos se radicalizem e se tornem universais, e o sofrimento, pelas limitações impostas pela ordem capitalista que agrava as condições de pobreza e fomenta a violência no avanço da barbárie.

Em cidades pequenas do interior das grandes capitais, as condições de trabalho dos assistentes sociais, bem como as políticas públicas, além de sofrerem os reflexos estruturais da crise do capital no que se referem às condições precarizadas de trabalho e o enfrentamento mínimo do poder público às mazelas sociais, a cultura política do paternalismo, da meritocracia e do clientelismo delineiam de forma específica o conservadorismo e as relações de subordinação na prática profissional e no enfrentamento à questão social.

A cidade de Parintins, localizada a 369 km da capital Manaus, no estado do Amazonas, tem ganhado projeção nacional e internacional através do festival folclórico dos bois-bumbás garantido e caprichoso que acontece anualmente e que traz a cada ano a proposta de valorização dos povos indígenas e tradicionais da Amazônia. No entanto, depois que o festival termina e as alegorias são desmontadas, a realidade social do município revela o descaso do poder público à questão social traduzido em uma política de "pão e circo", onde os assistentes sociais, reféns da precarização em sua grande maioria, precisam demonstrar competência, mas sem enfrentar de forma contundente o sistema, para se manterem empregadas e, assim, sobreviverem enquanto trabalhadoras.

Este artigo tem como objetivo problematizar os dilemas da atuação dos assistentes sociais nos diversos campos sócio-ocupacionais na cidade de Parintins - Amazonas a partir das condições institucionais de operacionalização da intervenção profissional, que conta com parcos recursos 
No fio da navalha: Entre a garantia dos direitos e a ameaça contra os próprios direitos na ...

para o atendimento de demandas cada vez mais crescentes e complexificadas e que colocam o assistente social no "fio da navalha" para atuar com providências na viabilização das demandas, no contexto de precarização do trabalho deste profissional, que precisa manter-se empregado para satisfazer suas necessidades básicas, muitas vezes sujeitando-se a condições arbitrárias que colocam em xeque o sentido e a direcionalidade do seu exercício profissional. Além disso, será problematizada a conduta ética dos assistentes sociais frente à violação dos direitos dos usuários, onde muitas vezes é orientada por valores conservadores e fundamentalistas que negam os princípios do projeto ético-político profissional.

Este estudo pauta-se metodologicamente em uma pesquisa de natureza qualitativa resultante de uma pesquisa de iniciação científica realizada no período de 2015 a 2016 por Viana (2016) e financiada pela Fundação de Amparo à Pesquisa do Estado do Amazonas - FAPEAM, que se propôs analisar as implicações das condições de trabalho dos assistentes sociais em Parintins - Amazonas e os reflexos sobre a sua subjetividade do profissional e o direcionamento de suas ações. Para isso, foi realizada pesquisa bibliográfica e de campo através da aplicação de um roteiro de entrevistas com 12 assistentes sociais da cidade de Parintins, inseridas nos espaços ocupacionais nas áreas da saúde, assistência social, sociojurídica, educação, previdência social e organizações não-governamentais (ONG's).

\section{Políticas sociais residuais e necessidades sociais exacerbadas na Ilha Tupinambarana}

Parintins é uma pequena cidade banhada pelo rio Amazonas e conhecida também como "Ilha Tupinambarana" em alusão aos índios Tupi, primeiros habitantes da região. A cidade localiza-se no baixo Amazonas e conta com uma população de 102.066 pessoas, segundo dados do IBGE (2010), tanto na área urbana quanto na zona rural (comunidades do entorno da cidade, em sua maioria, separadas pelo rio, cujo acesso ocorre somente por balsa ou lancha).

O festival folclórico de Parintins tem ostentado milhões todos os anos, mobilizando as três instâncias governamentais, o munícipio, o Estado e o governo federal, para "preparar" a cidade para os visitantes, garantindo o reforço da segurança, a qualidade dos serviços de saúde, saneamento, asfaltamento, dentre outros serviços sociais que amparem o turista. Passado o mês de junho, grande parcela da população parintinense volta a padecer com o descaso do poder público municipal na garantia dos mínimos sociais e na fragilização dos direitos trabalhistas. O censo do IBGE realizado no ano de 2010 apontou que em Parintins, 23,4\% das famílias encontram-se abaixo da linha de pobreza.

O aumento da pobreza e da miséria decorrentes do desemprego e/ou do vínculo de trabalho fragilizado leva grande parcela da população a recorrer às políticas sociais como forma de atenuar os efeitos agravantes das desigualdades sociais desencadeadas pela sociedade capitalista madura. O cenário econômico e político fortemente neoliberal reduz a ação do Estado ao mínimo traduzindo-se em intervenções pontuais sobre o social de forma focalizada, desarticulada e descontínua.

O esgarçamento das condições pauperizadas de vida dos mais pobres, a criminalização e a militarização da questão social, a ausência de uma reforma agrária, os sobrantes do capital que dificilmente encontram emprego ou voltam a se inserir no mundo do trabalho e os programas de transferência de renda sem a pretensão de se articularem a reformas estruturais representa o quadro traçado por Netto (2012) para mostrar os efeitos perversos do capitalismo globalizado sobre as condições de vida da maioria das pessoas que moram em países latino-americanos, como o Brasil.

Para Pereira (2008), a política, enquanto política pública, possui como marca principal justamente o fato de ser pública e não somente por estar vinculada ao Estado. Deve representar um conjunto de decisões e ações planejadas, pensadas e avaliadas pelo Estado e pela Sociedade visando à concretização de direitos sociais em favor do bem-estar da coletividade. Sua principal função é a concretização de direitos e a alocação e distribuição dos bens públicos que devem ser indivisíveis, públicos e de fácil acesso.

Porém, ao sofrerem os impactos estruturais do cenário econômico e político fortemente neoliberal aprofundados pelas raízes culturais brasileiras fundadas no paternalismo, no clientelismo e na meritocracia, a condição de direito 
social da política pública dilui-se no favor e no atendimento básico de necessidades imediatas.

A qualidade das políticas públicas ofertadas em Parintins é rebaixada, tanto pelos efeitos da política neoliberal de corte nos gastos públicos, quanto também pela centralização dos serviços de alta complexidade na capital Manaus. Na Amazônia, isso se torna um agravante pelas distâncias geográficas que separam os municípios do interior em relação à capital Manaus, cujas estradas são fluviais, em que o acesso é somente por barco e lancha, demorando até dois dias para se chegar à capital.

A rede de proteção básica e média complexidade em Parintins não dá conta das demandas agudizadas do desemprego e subemprego e da violação de direitos expressas nas mais diversas formas de violência contra a mulher e o idoso, o trabalho infantil, os atos infracionais cometidos por crianças e adolescentes e a exploração sexual infanto-juvenil. As ações de enfrentamento são mediatizadas pela seletividade na viabilização dos serviços sociais, em atendimentos individuais e ações socioeducativas não-sistemáticas, mecanismos paliativos por conta da desarticulação da rede socioassistencial. Nesse sentido, Sposati (2002, p. 49) afirma que as políticas sociais do Estado não têm a pretensão de promover autonomia e nem segurança aos usuários, pois "não são políticas sociais para cidadãos, são práticas e programas para necessitados".

A configuração do mercado de trabalho reforça a tendência salientada por Antunes e Praun (2015) do crescimento do setor de serviços a partir da década de 1990 orientada pelos reflexos da reestruturação produtiva com a flexibilização e a terceirização, tanto no setor público quanto no privado. Concorrem nesse contexto a gestão por metas, o trabalho informal, o assédio moral, as altas jornadas de trabalho e os processos de adoecimento e sofrimento.

A economia de Parintins é movimentada pelo funcionalismo público, por pequenas empresas de comércio e comerciantes de bebidas, estivas, roupas, calçados, assessórios, hotelaria e alimentação. Paralelo a isso, encontra-se também o trabalho informal de tricicleiros adultos e idosos (o triciclo é um meio de transporte muito comum em Parintins, que consiste em um veículo adaptado em forma de bicicleta que possui em sua parte dianteira uma carroceria para transportar pessoas), feirantes, moveleiros e carroceiros, o que traduz claramente uma cidade que entrecruza o tradicional e o moderno em suas relações de trabalho.

Como a maioria dos vínculos empregatícios são contratados pela gestão municipal, em tempos de crise financeira no Estado, os trabalhadores temporários e terceirizados são demitidos e, com isso, gera o efeito "cascata". Com o baixo poder de compra, os outros setores da economia são consequentemente atingidos, o que acirra as condições de pobreza e eleva os índices de criminalidade, refletidos nas mais diversas expressões da questão social.

$\mathrm{O}$ assistente social, enquanto trabalhador assalariado, também está inscrito no rol da precarização do trabalho, reflexos do toyotismo e os seus desdobramentos na flexibilização, terceirização e no trabalho temporário e sem garantia dos direitos trabalhistas (ANTUNES, 2006). Em Parintins, 92\% das contratações deste profissional estão na gestão pública, onde $45 \%$ das assistentes sociais são estatutárias e $55 \%$ com vínculo temporário, o que confirma a tendência apontada por lamamoto (2007) de que os vínculos empregatícios dos assistentes sociais majoritariamente se concentram na esfera pública governamental.

Como a maioria possui vínculo de trabaIho temporário, renovado a cada seis meses, as assistentes sociais se deparam com o dilema da instabilidade, pois ao mesmo tempo em que atuam no enfrentamento das expressões da questão social, também se identificam com as mesmas condições de fragilidade apresentadas em forma de demandas pelos usuários atendidos nas políticas públicas, estando igualmente sujeitas à demissão e a ameaça à reprodução da própria vida.

Em Parintins estão credenciadas, junto ao Conselho Regional de Serviço Social do Amazonas (CRESS-AM/RR 15 Região), 40 (quarenta) instituições de natureza pública e privada em que atuam 60 (sessenta) assistentes sociais (Silva, 2015), distribuídas nos espaços socio-ocupacionais nas áreas da Assistência Social $(25 \%)$, Saúde (25\%), Educação (25\%), Sociojurídica $(8,3 \%)$, Previdência Social $(8,3 \%)$ e Organizações Não-Governamentais - ONGs $(8,3 \%)$. 
No fio da navalha: Entre a garantia dos direitos e a ameaça contra os próprios direitos na ...

Cada espaço socio-ocupacional apresenta demandas específicas. Mas, em todas as áreas o que se nota é a prevalência de demandas pelos programas assistenciais e a violação de direitos nas mais diversas expressões, que quando são levados a conhecimento dos profissionais nas instituições, já se encontram violados.

$\mathrm{Na}$ área da Educação, as principais demandas estão ligadas a bolsas do programa nacional de assistência estudantil, esclarecimentos sobre os programas educacionais, demandas de gravidez precoce e evasão escolar.

Na Assistência Social, no âmbito da proteção básica, as solicitações ocorrem para a inserção nos programas de complementação alimentar, orientações dos programas assistenciais e denúncias de violação de direitos. $\mathrm{Na}$ proteção especial, as assistentes sociais recebem denúncias de violência contra os direitos da criança e do adolescente, da mulher, da pessoa com deficiência e contra o idoso. Além disso, executam as medidas de orientação nos casos de adolescentes em conflito com a lei.

Na Saúde, no nível de média complexidade, Parintins apresenta dois hospitais e um banco de sangue, cujas principais demandas, além da rotina hospitalar e atendimento à demanda espontânea, tem-se a viabilização do Tratamento Fora de Domicilio - TFD, uma vez que o município não dispõe do atendimento de alta complexidade. $\mathrm{O}$ trabalho educativo para a captação de doadores de sangue configura-se um desafio para desmitificar questões simbólicas tecidas no imaginário amazônico e outras questões de ordem sexista e preconceituosa.

$\mathrm{Na}$ atenção básica, as unidades de saúde não contam com assistentes sociais no quadro de atendimento. As profissionais que prestam serviço são do Nasf e recorrentemente afirmam que o trabalho do assistente social parece ser dispensável pela não procura dos usuários no setor de Serviço Social e porque os agentes comunitários de saúde, por terem um contato mais próximo à população, realizam uma intervenção que pode substituir a do Serviço Social. As profissionais afirmam intervir em caso de alguma orientação específica que o agente comunitário de saúde não tem conhecimento.

$\mathrm{Na}$ Previdência Social, as principais demandas são as orientações para o acesso e requerimento ao Benefício de Prestação
Continuada (BPC) e os direitos previdenciários, além de orientações de ordem jurídica e familiar, sobretudo nos casos de violência patrimonial. $\mathrm{Na}$ área Sociojurídica, as principais demandas que se apresentam ao Serviço Social são o atendimento de mulheres em situação de violência, idosos, crianças e adolescentes vitimas de abuso sexual e conflitos familiares para medidas de conciliação. Por fim, nas Organizações-Governamentais, presta-se orientação para o acesso aos benefícios e demandas institucionais.

O enfrentamento dessas demandas é condicionado muitas vezes pela disponibilidade dos recursos oferecidos pela instituição e geridos pela administração pública. A tendência do Estado mínimo para o social, com o corte nos gastos públicos e a racionalização da oferta (PEREIRA, 2008) impacta diretamente na qualidade dos serviços prestados a população e na autonomia do assistente social no direcionamento de suas ações.

O assistente social tem papel fundamental no processo de planejamento, administração e implementação das políticas sociais e públicas. De acordo com as diretrizes do projeto ético-político expressas também no Código de Ética de 1993 , o profissional deve atuar na defesa intransigente dos direitos humanos comprometendo-se com a qualidade dos serviços prestados a população na perspectiva da competência profissional.

Porém, isso não se dá de forma confortável. Ao contrário. As lutas empreendidas pelos assistentes sociais brasileiros vêm sendo fortemente balizadas pelas condições precarizadas de trabalho em que se inserem os profissionais, no aprofundamento das mazelas sociais e nas respostas cada vez mais insuficientes apresentadas pelas políticas sociais, base de sustentação funcional-ocupacional do trabalho do assistente social (MONTAÑO, 1997).

As medidas neoliberais na orientação das políticas públicas e sociais colocam em xeque a efetivação do projeto ético-político do assistente social, em alguns casos, confundindo a pertinácia em favor do compromisso ético-político em ações messiânicas e neoconservadoras, que a todo custo se empenham em contribuir para que o usuário tenha acesso aos serviços que demanda, como é possível observar no relato da assistente social a seguir: 
Já aconteceu de um aluno me agradecer porque contrariando o que a politica de assistência estudantil coloca, eu consegui incluí-lo em um programa junto com outros alunos que tinham reprovado e no final, ele veio me agradecer. Eu fiquei emocionada porque me senti feliz. A gente fica sensibilizada porque muitos alunos são pobres e apresentam grandes vulnerabilidades. Quando eu vou fazer visita domiciliar, me deparo com a situação precária em que muitos alunos estão inseridos. Ao mesmo tempo em que tenho que ser rígida, eu fico num conflito porque sei que a culpa deles serem reprovados não é só deles. Sei que cometi um ato de rebeldia, de incluir um aluno reprovado em um programa que só aceita aprovados, mas no final valeu a pena. Graças ao que eu fiz, hoje ele é um bom aluno (Ágata Rosa, 2016).

O posicionamento descrito no relato acima marca a postura de várias assistentes sociais em Parintins, que comprometidas com o seu projeto profissional, mas limitadas pelos parcos recursos institucionais para o atendimento das demandas dos usuários, extrapolam a carga horária de trabalho, trabalham fora dos dias de expediente na instituição e utilizam o próprio veículo custeando o combustível para a realização de visitas domiciliares, como forma também de "mostrarem serviço" e, assim, garantir a necessidade de sua permanência na instituição de que fazem parte, especialmente no caso das profissionais que trabalham em regime de contratação temporária.

Nota-se também o senso de obrigação moral com o "fazer o que é certo" diante do problema identificado, o que pode infringir as normas institucionais para a inclusão dos usuários nos programas oferecidos. Em decorrência disso, o sentimento de dever cumprido, do "sentir-se feliz porque conseguiu resolver o problema" traz o sentimento de culpa a posteriori pelo "ato de rebeldia" ao não considerar os meios para atingir os fins.

Essa postura é comumente associada ao messianismo, ao voluntarismo e reforça o neoconservadorismo na profissão. A intenção de ruptura apontada por Netto (2005) ainda se encontra em transitividade, pois os traços da ajuda, da benemerência, hoje travestidos por uma nova roupagem, ainda se encontram presentes no exercício profissional. Isso é reforçado pelo quadro de agudização da questão social, de onde se reforça uma postura humanista.

No cotidiano de intervenção, essas práticas pautam uma atuação profissional que reforça práticas de tutela e assistencialismo, como se a prestação dos serviços sociais dependesse da boa vontade do assistente social, que além de descaracterizar a viabilização dos serviços como direitos, quando os usuários não conseguem o atendimento às suas demandas, revoltam-se contra o assistente social esboçando reações de ameaças públicas que atingem a honra pessoal e profissional, podendo ocasionar a sua demissão.

\section{Dilemas, angústias e resistências na atuação do assistente social em Parintins}

Raichellis (2011) assinala que em um contexto societário de transformações no mundo do trabalho, caracterizado pela subcontratação, terceirização, precarização, retração dos direitos sociais e trabalhistas, é importante considerar as relações entre trabalho e adoecimento que repercutem na saúde do trabalhador, nas formas de objetivação e subjetivação do trabalho.

O assistente social, como trabalhador assalariado, não está imune aos processos desencadeados pela precarização do trabalho e consequentemente ao sofrimento e ao adoecimento físico e psicológico. O desrespeito à carga horária de trabalho, a extensão do trabalho institucional para o âmbito doméstico, reduzindo o tempo livre fora do trabalho, os baixos salários que estão aquém da satisfação das suas necessidades, a informalidade e os cargos genéricos são fatores que combinados com as ameaças recebidas pelos usuários no âmbito do exercício profissional e o assédio moral, levam o assistente social ao desenvolvimento de angústias, cansaço e podem propiciar posturas fatalistas ou messiânicas.

Problematizar a própria violação dos direitos dos assistentes sociais diante das suas condições de trabalho requer o entendimento e enfrentamento das dimensões complexas envolvidas nos processos e relações de trabalho em que se inserem os profissionais e onde se estabelece a tensão entre o projeto ético-político e a alienação do trabalho. Mascarar esses processos "é tornar indecifrável a precarização do trabalho, o elevado grau de sofrimento e frustração, a dilatação e a intensificação da jornada de 
No fio da navalha: Entre a garantia dos direitos e a ameaça contra os próprios direitos na ...

trabalho, a decadência geral das condições de vida" (ALENCAR e GRANEMANN, 2009, p 167).

Retoma-se, a partir disso, a indagação proposta pelo Conselho Federal do Assistentes Sociais (CFESS) como tema para a Semana do Assistente Social em 2012: "Como lutar pela garantia dos direitos dos outros se os meus próprios direitos estão sendo violados?".

Hennington (2011) aponta que a reestruturação produtiva impôs o surgimento de processos de trabalho onde a capacidade física, a cognição, a comunicação e a subjetividade do trabalhador tornaram-se elementos fundamentais porque são aviltados e explorados até o desgaste e descarte, assim como as coisas.

No caso dos assistentes sociais, a vinculação orgânica e ideopolítica com as classes subalternas parece perder a identidade quando o profissional, em uma postura de alteridade, não consegue se identificar com as condições rebaixadas de trabalho dos trabalhadores que são os usuários dos serviços sociais, como se somente o Outro, pela baixa qualificação e condições de vida marcadas pela pobreza e violação de direitos, fosse ser afetado pelo sofrimento e adoecimento. Para Raichellis (2011, p. 426):

O que se observa com maior frequência certamente em função da centralidade da classe operária na produção capitalista e dos inúmeros estudos sobre os impactos da reestruturação produtiva nas relações e condições de trabalho desta classe - é o assistente social analisar (e indignar-se) frente à exploração e ao desgaste a que são submetidos os trabalhadores assalariados, mas estabelecendo com estes uma relação de exterioridade $e$ de não pertencimento enquanto um segmento desta mesma classe.

Como trabalhador assalariado, que necessita vender a sua força de trabalho em troca de sua sobrevivência, o assistente social está exposto aos mesmos dilemas do conjunto da classe trabalhadora, inclusive dividindo as mesmas angústias que percorrem a condição de mulher e de mãe ao se deparar com a dupla jornada, os casos de violência contra a mulher, o aborto, o abuso e a violência sexual contra crianças e adolescentes. $\mathrm{O}$ assistente social está submetido aos mesmos dilemas e constrangimentos comuns a todos os trabalhadores assalariados, o que implica superar a relação dual e individual entre o profissional e os sujeitos aos quais presta serviços.

As determinações das condições de trabaIho precarizadas em que se inserem os assistentes sociais refletem sobre o direcionamento das ações desenvolvidas. A instabilidade do vínculo empregatício contribui para a baixa qualidade dos serviços prestados, a descontinuidade das ações e a autonomia do profissional. Para não serem demitidas, Viana (2016) demonstra que algumas profissionais se amoldam às pressões porque dependem financeiramente desse trabalho para manter as suas famílias, conforme explicitado nos seguintes relatos:

Quando você não tem um vínculo mais seguro, isso vai influenciar no seu exercício profissional. Não estimula a fazer um trabalho melhor, às vezes é difícil dar continuidade às ações porque a qualquer momento podem me mandar embora. A minha contrapartida é dar o meu melhor para que os gestores continuem percebendo que eles vão precisar de mim (Esmeralda, 2016).

Quem vive de contrato, está sempre sob pressão porque você não sabe até quando vai ficar, não tem estabilidade. Eu espero passar em um concurso para ter estabilidade porque eu não posso viver a mercê de situações que podem me demitir a qualquer hora. Não é justo com a profissional que eu sou e nem comigo enquanto pessoa (Turmalina, 2016).

A fala de Esmeralda ilustra preocupação em assegurar o vínculo de trabalho e a busca de um bom desempenho contínuo para se mostrar necessária ao empregador, temerosa em perder o vínculo de trabalho temporário. Han (2015) ao analisar a sociedade ocidental como a sociedade do cansaço, afirma que os trabalhadores estão inseridos em uma rotina frenética de trabalho, sem tempo para o ócio criativo. Essa rotina tem levado ao adoecimento pelo cansaço, através da depressão, da ansiedade, do estresse e das doenças cardíacas. O excesso de pressão, como é possível observar no relato em questão, subtrai o tempo livre do trabalhador e o leva a uma corrida desesperada pelo excesso de positividade.

A contratação e a demissão da maioria das assistentes sociais em Parintins, segundo Viana (2016), dependem da vontade do governante que está no poder, uma vez que a maioria das instituições em que atuam as profissionais 
está sob a responsabilidade da gestão municipal. Essa arbitrariedade fragiliza a solidariedade de classe e a organização política da categoria à medida que as assistentes sociais estão no fio da navalha. Caso se posicionem politicamente contra as decisões do governo municipal ou não se submetam a certas atribuições, como algumas que não são específicas do Serviço Social, correm o risco de serem demitidas e rapidamente substituídas.

Por ser contratada, por muitas vezes alguns colegas serem "puxa saco" do prefeito, algumas situações que nós falamos aqui, eles entendem de outra forma e levam aos gestores ou pessoas próximas da administração pública. A gente acaba se inibindo de expressar certos posicionamentos com medo de ser "derrubada" (Topázio Azul, 2016).

As novas formas de gestão do trabalho incluem o assédio moral como forma de controle dos trabalhadores, conforme ilustrado no relato de Topázio Azul. Silva e Raichellis (2015) afirmam que o assédio moral pode ser tanto entre os assistentes sociais, como reflexo da competitividade e da fragilização da solidariedade entre os trabalhadores, como também pode ser desencadeado por um profissional que se encontra em uma posição de superioridade contra outra que em situação de subalternidade. $O$ assédio moral ofende o projeto ético-político do Serviço Social e se materializa em ações de difamação, perseguição e isolamento dos profissionais que se empenham na efetivação de suas ações com competência, sobretudo quando ameaçam o "equilíbrio" institucional, podendo resultar em demissão, se o vínculo de trabalho não for legitimado por concurso público.

Quando perguntadas sobre quais os principais desafios encontrados nas diversas instituições para o desenvolvimento do seu trabalho, as assistentes sociais disseram que os vínculos empregatícios fragilizados, em especial os contratos temporários, interferem na continuidade das atividades realizadas; a indisponibilidade do transporte, pois na maioria das instituições não há um transporte próprio, o que faz com que muitas vezes o profissional utilize seu próprio veículo; a falta de uma sala própria para o atendimento dos usuários, o que compromete o sigilo profissional; a falta de qualificação profissional oferecida pela gestão municipal e as dificuldades em participar de capacitações oferecidas por outras entidades em razão da não-liberação da profissional e a desvalorização salarial (VIANA, 2016).

A questão salarial é discrepante de uma área para outra. A pesquisa em Parintins mostra que $67 \%$ das assistentes sociais recebem de 1 a 3 salários mínimos e estão alocadas em vínculos temporários por contratos de trabalho nas áreas da Saúde, Sociojurídica, Educação, Organizações Não-Governamentais e instituições de Assistência Social; 25\% das profissionais estatutárias recebem de 6 a 10 salários e estão na área da Saúde, Educação e Previdência Social (governo federal) e $8 \%$ das assistentes sociais, que estão inseridas na área da Educação no âmbito do governo federal, recebem de 4 a 7 salários mínimos.

Esses dados confirmam que os profissionais terceirizados são os que recebem menor remuneração e maior sobrecarga de trabalho, conforme Antunes (2015). As assistentes sociais entrevistadas consideram injustos os baixos salários recebidos pelos profissionais contratados temporariamente, sobretudo os que atuam na política de assistência social, que se deparam cotidianamente com problemáticas e crescentes demandas de pobreza e violação de direitos, o que leva a um sentimento de frustração por não corresponder ao atendimento de suas necessidades pessoais. A indefinição do piso salarial também contribui para o rebaixamento de salários. Para Turmalina, "muitas vezes o gestor paga o valor que ele acha que deve pagar. Eu passei mais de quatros anos na universidade $\mathrm{e}$ às vezes me sinto humilhada pelo salário que recebo" (VIANA, 2016).

Um outro fator que se destaca na questão de violação dos direitos dos assistentes sociais em Parintins concerne ao desrespeito à carga horária de 30 horas semanais estabelecida em lei. A Lei $n^{\circ} 12.317$ de 26 de agosto de 2010 foi uma grande conquista para o Serviço Social, pois determina a carga horária de trabalho do assistente social em 30 horas semanais (CFESS, 2010), possibilitando assim "diminuir a sobrecarga do trabalho, o que pode melhorar a saúde do(a) trabalhador(a) e, ainda impor limites à exploração do trabalho pelo capital" (BOSCHETTI, 2011, p.567). 
A pesquisa de Viana (2016) revela ainda que $8 \%$ das profissionais possuem carga horaria de 20 horas semanais; $67 \%$ carga horaria de 30 horas semanais e $25 \%$ trabalham 40 horas semanais. Percebe-se que, apesar da existência da lei $n^{\circ} 12.317$, no município de Parintins ainda há profissionais que excedem a carga horária de 30 horas. Nesse caso, as profissionais que trabalham em caráter temporário cumprem 30 horas semanais enquanto as que se encontram em regime estatutário efetivo, trabalham 40 horas.

A compreensão das assistentes sociais entrevistadas quanto ao regime de 40 horas de trabalho expressa que quando prestaram o concurso público a nível federal, já estava estabelecida a carga horária de 40 horas. No caso das assistentes sociais que trabalham em vínculo temporário, a conquista das 30 horas de trabalho foi negociada entre o CRESS e a Prefeitura. As assistentes sociais tinham "medo" do "julgamento" dos demais profissionais, caso reivindicassem a redução para 30 horas semanais. A fiscalização do CRESS-AM contribuiu para o cumprimento da normativa, conforme o seguinte relato de uma assistente social:

Estávamos trabalhando 8 horas por dia, era uma preocupação, um medo de falarem que só estivéssemos trabalhando 6 horas, pois é muito relativo, uns colegas entendem e outros não. O CRESS veio aqui e nós falamos para eles, que conversaram com o Secretário responsável e ficou decidido trabalharmos só 6 horas por dia, cumprindo 30 horas semanais (Topázio Azul, 2016).

É preciso que haja uma maior atuação nesse sentido do Conselho Regional de Serviço Social do Amazonas junto às profissionais estatutárias que trabalham 40 horas semanais, pois assim como houve a negociação da carga horária das profissionais em caráter temporário, muitos outros poderiam ter a mesma resolutividade e estariam cumprindo somente as 30 horas semanais estabelecidas em lei.

A Lei de Regulamentação da Profissão em seu Art. $7^{\circ}$ reconhece o Conselho Federal de Serviço Social (CFESS) e os Conselhos Regionais de Serviço Social (CRESS) como instituições representativas da categoria, com o objetivo básico de disciplinar e defender o exercício da profissão de Assistente Social em todo o território nacional e estabelecendo suas competências no Art. $10^{\circ}$ :

I - Organizar e manter o registro profissional dos Assistentes Sociais e o cadastro das instituições e obras sociais públicas e privadas, ou de fins filantrópicos;

II - Fiscalizar e disciplinar o exercício da profissão de Assistente Social na respectiva região;

III - expedir carteiras profissionais de Assistentes Sociais, fixando a respectiva taxa;

IV - Zelar pela observância do Código de Ética Profissional, funcionando como Tribunais Regionais de Ética Profissional;

V - Aplicar as sanções previstas no Código de Ética Profissional;

VI - Fixar, em assembleia da categoria, as anuidades que devem ser pagas pelos Assistentes Sociais;

VII - Elaborar o respectivo Regimento Interno e submetê-lo a exame e aprovação do fórum máximo de deliberação do conjunto CFESS/ CRESS.

Os relatos das assistentes sociais entrevistadas evidenciam grande insatisfação com o CRESS-AM. A quase inexistência de fiscalização das condições de trabalho dos assistentes sociais de Parintins por parte do Conselho Regional é destacada pelas assistentes sociais. Na maioria dos casos, as profissionais referem que não são comunicadas quando a comissão de fiscalização do CRESS está no município, e quando procuram alguma orientação ou realizam alguma denúncia, não são atendidas com êxito.

Não vejo o CRESS-AM como uma instituição presente. Fica difícil cobrar uma reunião se eles mesmos não se programam para isso. É um Conselho ausente e só aparecem em Parintins no período que alguma chapa precisa ser eleita. Penso que o CRESS deveria ser muito mais atuante porque isso só enriqueceria nossa categoria (Pedra do sol, 2016)

O conselho é muito ausente, quase não aparece em Parintins. Durante esse período que estou aqui, só vieram uma vez. Eles só fazem aumentar a anuidade, mas não mandam pelo menos uma agenda, não tem fiscalização. Precisamos unir nossa categoria para cobrar essas coisas, a nossa categoria não está unida (Celestita, 2016) 
$\mathrm{Na}$ minha visão, a atuação do CRESS-AM é horrível. Eu faço o possível para trabalhar com o meu registro em dia. Já vi colegas trabalhando sem o registro em dia e que não poderiam estar trabalhando. Eu já denunciei, mas nenhuma providência foi tomada, então eu já pensei em não pagar mais para ver qual seria a nossa punição, mas aí volto atrás; penso que não é porque eles estão errados que eu também vou estar. Deveriam fiscalizar, notificar para que a classe se fortaleça (Jade, 2016)

É preciso uma maior atuação do Conselho no município, assim como a promoção de cursos de capacitação e a presença nos eventos realizados. Parintins conta com uma universidade federal e uma instituição privada, que formam a cada ano um contingente significativo de assistentes sociais, que são absorvidos pelas 40 instituições reconhecidas pelo CRESS-AM no município. A proposição do Conselho Regional consiste em zelar pelo cumprimento do código de ética profissional, o que inclui a fiscalização das condições de trabalho e do exercício profissional (LEI 8.662/1993).

As lutas travadas pelas assistentes sociais em Parintins vêm sendo fortemente balizadas pelas condições precarizadas de trabalho em que se inserem as profissionais, mas também pelo aprofundamento das mazelas sociais e nas respostas cada vez mais insuficientes apresentadas pelas políticas sociais. Os parcos recursos para o atendimento de uma questão social maximizada leva à seletividade no atendimento, em que o assistente social acaba se tornando um "juiz rigoroso da pobreza". Para lamamoto (2007, p. 161):

Esse quadro tem sido fonte de angústias e questionamentos sobre o nosso papel profissional diante da dificuldade de criar, recriar e implementar propostas de trabalho podendo estimular a burocratização e o vazio profissional. Alguns buscam, como "tábua de salvação", o discurso do mero "compromisso com a população", seja em sua versão mais politizada, seja em sua versão dialógica do respeito ao homem, como o apoio possível, mas incapaz, por si só, de enfrentar as demandas materiais e socioculturais da população trabalhadora.
O vínculo de trabalho fragilizado repercute diretamente no sentido e na direcionalidade do trabalho profissional. Segundo Prates (1995), a teleologia no trabalho do assistente social permite ao profissional planejar consciente e criticamente as suas ações profissionais de modo a orientar a sua intervenção profissional em uma perspectiva dialético-crítica com viés transformador.

Em um contexto de precarização do trabaIho de onde se demanda um profissional mero executor de tarefas, a instrumentalidade da ação profissional se dilui no esvaziamento da intencionalidade no uso dos instrumentais técnico-operativos. As técnicas de gestão e planejamento, assim, dificilmente conseguem se converter em ações de médio e longo prazos para a percepção de impactos nas condições de vida dos sujeitos sociais, mas reduzem-se a ações de curto prazo, imediatistas e pragmáticas.

Quando questionadas sobre a satisfação com o seu trabalho, as entrevistas da pesquisa de Viana (2016) apresentaram uma dualidade nas respostas. De um lado, profissionais que, apesar das dificuldades, se dizem muito satisfeitas com o seu trabalho e de outro, assistentes sociais que relatam insatisfação por conta do excesso de trabalho, pelas barreiras institucionais e os baixos salários.

Apesar das resistências institucionais que se apresentam como barreiras para a viabilização da demanda do usuário, a busca de estratégias pelos assistentes sociais revela o compromisso profissional com a resolutividade da demanda e a concretização dos direitos. O empenho das assistentes sociais reafirma o que lamamoto (2007) defende, que o profissional é guiado por valores nobres e humanistas, indignado pelas injustiças sociais. E que, por isso, a maior satisfação nessa profissão é a contribuição para a construção de uma nova sociabilidade, que se inicia pela efetivação dos direitos, conforme demonstrado na seguinte fala:

A maioria dos casos a gente leva para casa, tem casos que nos deixam frustrados, que a gente chora, sofre junto, não na frente da pessoa. Muitas vezes, a gente fica abalada, pois não temos como ajudar a não ser se a pessoa se auto-ajudar. Eu me lembro de um caso que a gente atendeu recentemente; era uma família que tinha sido despejada e a gente precisava alugar uma casa para eles, mas 
não encontrávamos. Andamos sábado e domingo. Por mais que não fosse o dia do nosso trabalho, a gente ia por conta do compromisso que a gente tinha com aquela família, que era muito grande. No primeiro e segundo dia não achamos, mas no terceiro dia a gente achou uma casa e foi nesse dia que eu fiquei super estressada, eu já estava adoecendo e fui aliviar toda a minha tensão e preocupação quando eu cheguei em casa e chorei, agradeci a Deus e pronto (Topázio Azul, 2016).

A pesquisa realizada por Viana (2016) aponta angústias que permeiam o trabalho de algumas assistentes sociais. São questões não resolvidas no campo da ética profissional, que muitas vezes culmina em posturas preconceituosas e arbitrárias e que tolhe os direitos dos usuários (BONETTI, 2007). Esses conflitos advêm da vinculação do caso com a identificação pessoal da profissional no papel de mãe e mulher.

Os casos de abuso e exploração de criança eu não atendo. Eu sei que eu preciso mudar. Não sei se é pelo fato de ter um filho, mas eu não consigo fazer esses atendimentos. Os casos de maus-tratos me deixam pensativa, mas até consigo atender, menos abuso sexual de criança (Rubi, 2016).

Outros conflitos se colocam na ordem do moralismo ético e religioso. Há relatos de outras assistentes sociais, que não fizeram parte da pesquisa de Viana (2016), que dizem não conseguir orientar casos de aborto em situações autorizadas por lei, como de violência sexual, porque entendem que se trata de um crime contra a vida, e quando orientam, ao sair do trabalho, correm para se confessar na igreja por entender terem violado a sua própria ética religiosa. Em uma entrevista realizada com uma profissional em Parintins, ela se reportava a conduta de seu estagiário homossexual nas redes sociais como inapropriada e exposta, o que desqualificava a sua moral nos serviços prestados no ambiente de trabalho junto aos usuários. Essas posturas infringem os princípios do projeto ético-político e reproduzem uma postura profissional deslocada das lutas dos movimentos sociais, reiterativas de formas de dominação conservadoras burguesas.

O neoconservadorismo na prática do Serviço Social, aponta Pinheiro (2015), permeia a visão dos assistentes sociais desde antes da formação profissional e, no contexto desta, é reapropriado na perspectiva de teorias religiosas, que vinculam-se à uma mística de salvação do mundo e na construção de uma nova ordem social. As questões de fundo moral que se chocam com preceitos cristãos, são enfrentadas pelo convencimento à adequação de padrões conservadores, o que se traduz em uma postura heroica e messiânica de salvar o mundo das mazelas ocasionadas pela maldade de algumas pessoas contra outras.

Outras angústias se referem às ameaças sofridas pelas assistentes sociais no atendimento a algumas demandas. Como o profissional atua como executor direto das políticas sociais, ao negar o benefício demandado, não por má vontade, mas pelo fato do usuário não atender aos critérios estabelecidos pela política social, é ameaçado. Quando isso acontece, alguns usuários ameaçam ir às rádios e falar sobre a questão, principalmente em tempos de campanha eleitoral no município. Por vezes, os nomes de algumas assistentes sociais são falados nas rádios, o que pode resultar em demissão, e outras profissionais são processadas.

Em outros momentos, as ameaças ocorrem durante a visita domiciliar, entendida por alguns usuários como "investigação policial" onde o assistente social é o denunciante que vai "levar alguém preso". As assistentes sociais relatam serem expulsas das casas e/ou recebidas de forma grosseira e ameaçadas de forma explícita, onde é dito que "não é da conta da assistente social o que acontece. Por isso, ela não deve se meter no caso". Observemos o registro a seguir:

Eu fui fazer uma visita e na hora de orientar, o responsável pelo idoso se alterou bastante, falou as piores coisas para mim, quase fui agredida fisicamente por ele, porque verbalmente fui agredida, aí eu fui à delegacia para registrar um boletim de ocorrência. Acabei "deixando para lá" porque foi um caso que me chamou muito a atenção e entendi ser muito mais viável fazer um acordo com ele do que levar a situação adiante porque eu queria acompanhar aquele idoso e se eu levasse o caso mais a frente contra o agressor, eu não poderia acompanhar mais aquele caso. Fizemos um acordo para eu continuar indo lá visitá-lo (Rubi, 2016). 
Essas ameaças comprometem a segurança das profissionais. Por um lado, muitos usuários entendem que o trabalho do assistente social tem cariz de "ajuda" que deve ser viabilizada a qualquer custo e, quando isso não acontece, a profissional é acusada como "culpada" por não autorizar o acesso ao benefício, o que faz com que muitas assistentes sociais recorram a manobras diversas até resolverem o caso em questão, como parte de uma missão heroica. Por outro lado, as profissionais são vistas como agentes do governo com o poder de decisão sobre a liberdade do usuário, que trabalham para fiscalizar a vida das pessoas com a intenção de readequá-las a uma forma de comportamento indesejado por elas.

\section{Considerações Finais}

A problematização que cerca o trabalho do assistente social é um campo que ainda requer muitas reflexões e estudos, com a finalidade de conhecer, analisar e objetivar o mundo do trabaIho em que se insere este profissional, sujeito a determinações institucionais, políticas, ideológicas, econômicas e sociais. É de incontestável importância conhecer esse universo em que os assistentes sociais estão inseridos, principalmente no que tange seu exercício profissional, possibilidades, desafios e perspectivas, especialmente porque como trabalhador comprometido com a garantia dos direitos sociais, precisa também ter seus direitos respeitados.

O conjunto de modificações na esfera produtiva incide sobre as formas de gestão da força de trabalho e, consequentemente, sobre as políticas públicas. Em tempos de crise estrutural do capital, as expressões da questão social agravadas pela precarização das relações de trabalho são assaz explícitas, afetando diretamente as condições, relações e o exercício do profissional.

Quando observadas no município de Parintins, destacam-se as influências de uma gestão pública marcada fortemente por uma cultura paternalista e meritocrática, onde a maioria dos assistentes sociais são contratados pelas instituições por contrato temporário, adoecendo e sofrendo com a instabilidade no emprego, a sobrecarga de trabalho, os baixos salários e as demissões em suspenso que pautam uma conduta vigilante.
São profissionais que sofrem ameaças pela seletividade das políticas públicas ao terem que incluir o "pobre do mais pobre" e também no empenho da realização do exercício profissional, no combate às formas de violência, autoritarismo e arbítrio. Por isso, são profissionais que se encontram no "fio da navalha" que, na busca de concretização de direitos dos usuários tem seus próprios direitos ameaçados e/ou violados.

A quase inexistência de fiscalização das condições de trabalho dos assistentes sociais de Parintins por parte do CRESS/AM merece destaque, bem como a necessidade de promoção de cursos de capacitação e a presença nos eventos realizados no município. As queixas por uma presença mais atuante do Conselho Regional poderiam inibir as ameaças de assédio moral e resguardar a segurança do assistente social no âmbito do seu exercício profissional.

A atenção ao sujeito profissional é imprescindível para desvelar as condições insalubres de trabalho em que muitos assistentes sociais estão inseridos por conta das relações precarizadas de trabalho que atingem a si próprios e os usuários que atendem, com demandas cada mais complexas no contexto do aprofundamento da pobreza e nas mais diversas formas de violação dos direitos. Desprezar a subjetividade do profissional, não levando em conta as suas angústias e sofrimentos, é enfraquecer a identidade profissional e o vínculo orgânico da profissão com as lutas sociais.

\section{Referências}

ALENCAR, Mônica Maria Torres de; GRANEMANN Sara. Ofensiva do capital e novas determinações do trabalho profissional. Revista Katálysis. Florianópolis, v.12 n. 2, p. 161-169 jul./dez. 2009;

ANTUNES, Ricardo. Adeus ao trabalho? Ensaio sobre as metamorfoses e a centralidade do mundo do trabalho. São Paulo: Cortez / Campinas: Universidade Estadual de Campinas, 2006;

; PRAUN, Luci. A sociedade

dos adoecimentos no trabalho. Revista Serviço Social e Sociedade. São Paulo, n. 123, p. 407-427, jul./set., 2015;

BRASIL. Instituto Brasileiro de Geografia e Estatística, 2010; 
No fio da navalha: Entre a garantia dos direitos e a ameaça contra os próprios direitos na ...

BRASIL. Lei de Regulamentação da Profissão de Assistente Social - 8.662/1993;

BONETTI, Dilséa Adeodata; SILVA, Marlise Vinagre et. al. Serviço Social e Ética: Convite a uma nova práxis. $8^{a}$ edição. São Paulo: Cortez, 2007;

BOSCHETTI, Ivanete. Condições de trabalho e a luta dos(as) assistentes sociais pela jornada semanal de $\mathbf{3 0}$ horas. Revista Serviço Social \& Sociedade. São Paulo, n. 107, p. 557 a 584, ano de 2011;

CASTELLS, Robert. Desigualdade e a questão social. São Paulo: EDUC, 2008;

CRESS, Conselho Regional de Serviço Social. Coletânea de Leis. Conselho Regional de Serviço Social: $15^{\mathrm{a}}$ Região Amazonas/Roraima. $2^{\mathrm{a}}$ edição. Manaus: Valer, 2010;

HAN, Byung-Chul. Sociedade do cansaço. Tradução: Enio Paulo Gianchini. Editora Vozes, 2015;

HENNINGTON, Élida Azevedo. Entre o criativo e o precário: reflexões sobre constrangimentos e possibilidades do trabalhador da saúde em tempos líquidos. In: MINAYO GOMES, Carlos (org.). Saúde do trabalhador na sociedade brasileira contemporânea. Rio de Janeiro: Fiocruz, 2011;

IAMAMOTO, Marilda Vilela. O Serviço Social na contemporaneidade: formação e trabalho profissional. $11^{a}$ edição. São Paulo: Cortez, 2007;

MONTAÑO, Carlos. O Serviço Social frente ao neoliberalismo: mudanças na sua base de sustentação funcional-ocupacional. In: Revista Serviço Social \& Sociedade, n. 53, 1997;

NETTO, José Paulo. O movimento de reconceituação: 40 anos depois. In: Revista Serviço Social \& Sociedade. Ano XXVI, ${ }^{\circ}$ 84, novembro de 2005;

Crise do capital e consequências societárias. Revista Serviço Social \& Sociedade. São Paulo, n. 111, p. 413-429, jul./set. 2012;

PEREIRA, Potyara Amazoneida Pereira. Discussões conceituais sobre política social como política pública e direito de cidadania. In: BOSCHETTI, Ivanete; BEHRING, Elaine Rossetti et. al. Política social no capitalismo: Tendências contemporâneas. São Paulo: Cortez, 2008;

PINHEIRO, Paulo Wescley Maia. Serviço Social, neoconservadorismo religioso e o desafio para a formação profissional. Revista Temporalis, Brasília, ano 15, n. 29, p. 195-220, jan./jun., 2015;
PRATES, Jane Cruz. A questão dos instrumentais técnico-operativos numa perspectiva dialético-crítica de inspiração marxiana. In: Gestão estratégica de instituições sociais: o método marxiano como mediação do projeto político. Dissertação de mestrado. Faculdade de Serviço Social, PUC-RS, Porto Alegre, 1995;

RAICHELLIS, Raquel. O assistente social com trabalhador assalariado: desafios frente às violações de seus direitos. Serv. Soc. Soc., São Paulo, n. 07, p.420-437, jul./set.2011.

SILVA, Adriana Lemos da. A viagem de volta: pesquisa e produção de conhecimento no trabalho do assistente social em Parintins - AM. TCC de graduação em Serviço Social. Universidade Federal do Amazonas: Instituto de Ciências Sociais, Educação e Zootecnia de Parintins. Parintins, 2015;

SILVA, Ociana Deodato da; RAICHELLIS, Raquel. $O$ assédio moral nas relações de trabalho do assistente social: uma questão emergente. In: Revista Serviço Social \& Sociedade. São Paulo: $\mathrm{n}^{\circ}$ 123, p. 582-603, jul./set., 2015;

SPOSATI, Aldaíza. Regulação social tardia: características das políticas sociais latino-americanas na passagem entre o segundo e o terceiro milênio. In: Políticas sociais para um novo mundo necessário e possível. Caderno ideação. Porto Alegre: Fórum Social Mundial, 2002;

VIANA, Beatriz Borges. Entre o prazer e o sofrimento: um estudo sobre as condições de trabalho do assistente social em Parintins - AM e as implicações sobre a subjetividade do profissional e o direcionamento de suas ações. Orientadora: Professora Mestre Alice Alves Menezes Ponce de Leão Nonato. Universidade Federal do Amazonas, Instituto de Ciências Sociais, Educação e Zootecnia de Parintins. Área: Ciências Sociais Aplicadas. Financiamento: Fundação de Amparo à Pesquisa no estado do Amazonas. Parintins, 2016. 